\title{
Signatures of Sudden Storm Commencement on the equatorial thermospheric dayglow
}

\author{
Sukumarn N. G. K. Sumod ${ }^{1,2, *}$, Tarun K. Pant ${ }^{1}$, and Asokan P. Ajesh ${ }^{1}$ \\ ${ }^{1}$ Space Physics Laboratory, Indian Space Research Organization, Trivandrum 695022, India \\ ${ }^{2}$ Space Science Group, Sacred Heart College, Mahatma Gandhi University, Kochi 682 013, India
}

Received 5 January 2019 / Accepted 17 June 2019

\begin{abstract}
It has been observed that the OI $630.0 \mathrm{~nm}$ dayglow emission over a dip equatorial station, Trivandrum $\left(8.5^{\circ} \mathrm{N}, 77^{\circ} \mathrm{E}\right.$, dip $\left.0.5^{\circ} \mathrm{N}\right)$, India registered an abrupt increase of $\sim 2000 \mathrm{R}$ during the compression phase of the magnetosphere as dictated by a sudden increase in solar wind ram pressure. Furthermore, an unusual depletion of these emissions has been observed during the eastward interplanetary electric field (IEF), concomitant with southward excursion of IMF Bz. The ionosonde and magnetometer observations confirmed the effects of prompt penetration electric field (PPEF). Associated with the eastward PPEF, formation of F3 layers were also noticed. These unique results, which emphasize the effect of Sudden Storm Commencement/IEF on these equatorial daytime airglow emissions are discussed in context of changes in the equatorial zonal electric field and $\mathrm{F}$ region height variations associated with polar/auroral activities due to the magnetosphere-ionosphere coupling.
\end{abstract}

Keywords: Dayglow / equatorial electrodynamics / Sudden Storm Commencement

\section{Introduction}

The neutral OI $630.0 \mathrm{~nm}$ thermospheric airglow has been used as a reliable tracer to address many of the equatorial/low latitude ionospheric neutral and electrodynamic phenomena during both geomagnetically quiet and disturbed periods, particularly during night time. On the other hand, during daytime, detection of these faint emission features buried in the bright solar continuum is really a challenging task (Chakrabarti, 1998). However, recent innovations in the form of daytime spectro/photometry have brought out significant results pertaining to low latitude/equatorial thermosphere-ionosphere system (TIS), particularly during geomagnetically quiet periods (Sridharan et al., 1998; Pallamraju et al., 2002; Sumod et al., 2012). For instance, Sridharan et al. (1992) has reported that, over the crest region of equatorial ionization anomaly (EIA), dissociative recombination of $\mathrm{O}_{2}^{+}$with ambient electrons is mainly responsible for the observed temporal variability in the dayglow. Based on this work, the temporal evolution and spatial extent of EIA over the Indian sector were studied in detail using high resolution two-D maps of OI $630.0 \mathrm{~nm}$ dayglow measurements (Pallamraju \& Sridharan, 1998). In another study, it was understood that the shape of the diurnal pattern of these

\footnotetext{
*Corresponding author: sgsumodh@gmail. com
}

dayglow intensity variation has a definite relation with the strength of equatorial electrojet (EEJ) (Chakrabarty et al., 2002). The importance of OI $630.0 \mathrm{~nm}$ dayglow in: (i) identifying the precursor to equatorial spread-F (ESF) (Sridharan et al., 1994) and (ii) understanding the role of Gravity Waves as seed perturbations to ESF (Sreeja et al., 2009a) were also reported. Similarly, these dayglow observations have been successfully employed to investigate short and long duration thermospheric waves (Pallamraju et al., 2014).

In addition to the afore-mentioned quiet time results, OI $630.0 \mathrm{~nm}$ emission have brought out significant results associated with many space weather issues and understanding of high latitude-low latitude coupling. For instance, Sridharan et al. (1999) reported the effect of the space weather event of January 6, 1997 on $630 \mathrm{~nm}$ dayglow emissions over a low latitude station when the magnetosphere was compressed to $<6 R_{\mathrm{E}}$. Pallamraju et al. (2004) inferred the imprints of composition changes in these airglow emissions associated with a geomagnetic storm, from a low-latitude station. Different modes of acoustic gravity waves during magnetically quiet and disturbed times have also been separated using these daytime airglow features (Chakrabarty et al., 2004). Recently, the effect of substorm induced changes in these dayglow emissions over Mt. Abu (magnetic latitude: $16.2{ }^{\circ} \mathrm{N}$ ) has been investigated (Chakrabarty et al., 2010). Similarly, concomitant changes in 
these dayglow during an $X$-class solar flare were also observed in many of the earlier studies (e.g., Das et al., 2010). Sumod et al. (2014) have reported prompt and delayed effects of these optical emissions over a dip equatorial station, associated with solar flares of different ranks. Very recently, concurrent variability of the equatorial ionosphere and mesopause in the context of a number of penetration events has also been presented in the literature (Sumod et al., 2015).

Nevertheless, the effect of sudden storm commencement (SSC) on these thermospheric emissions has not been understood until now, primarily due to the paucity of high cadence data. In this background, this work, probably for the "first time" addresses the effect of SSC and long duration prompt penetration IEF on the time variability of the ground based atomic oxygen emissions over the dip equator.

\section{Experiment}

A multi wavelength dayglow photometer (MWDPM) developed indigenously in India has provided systematic measurements of thermospheric and mesospheric airglow during daylight hours, since 2004 onwards. These measurements have provided significant results concerning coupling processes in the equatorial upper atmosphere (e.g., Sumod et al., 2011a, b). The OI $630.0 \mathrm{~nm}$ dayglow emission, as obtained by using this unique photometer over a magnetic dip equatorial station Trivandrum $\left(8.5^{\circ} \mathrm{N}, 77^{\circ} \mathrm{E}\right.$, dip $\left.0.5^{\circ} \mathrm{N}\right)$, has been used for the present study. The system details and data analysis methodology have already been published elsewhere (Sridharan et al., 1998). On August 24, 2005, MWDPM was operated in the scanning mode to study the spatio-temporal evolution of OI $630.0 \mathrm{~nm}$ emission features in context of equatorial ionization anomaly (EIA). These measurements were made between 09:00 IST and 18:00 IST at four different elevations south of Trivandrum, the minimum elevation being $66^{\circ}$ and maximum $90^{\circ}$. The maximum horizontal distance covered in this configuration is $471 \mathrm{~km}$, by assuming that the $\mathrm{O}\left({ }^{1} \mathrm{D}\right)$ profile peaks at $\sim 240 \mathrm{~km}$. Although this study is mainly intended to understand the effect of SSC/IEF on the daytime evolution of these neutral airglow, all the observations corresponding to different elevations from Trivandrum in the southern direction with a resolution of $\sim 5 \mathrm{~min}$ are presented here. The dayglow intensities are presented in units of Rayleigh (R), by following the same methodology of Sumod et al. (2014). It must be mentioned that the relative increase/decrease in the dayglow at different elevations are the dynamical features associated with the EIA and are not discussed here. The prevailing conditions in the solar windmagnetosphere system on August 24, $2005\left(A_{p}=102\right)$, has been analyzed using the data, obtained from the OMNI website. These data have already been time shifted from the 1st libration point to the nose of the bow-shock at the magnetosphere. For the present investigation, all the data products averaged for $5 \mathrm{~min}$. are considered. The details of the data processing and time shifting techniques are available in OMNI site (http:// omniweb.gsfc.nasa.gov/). In addition to these, coordinated measurements of F2 peak height variation $(\mathrm{hmF} 2)$ as scaled from the $15 \mathrm{~min}$. ionograms using a KEL ionosonde are presented here. One minute values of the strength of EEJ over Indian longitudes as obtained by subtracting horizontal geomagnetic fields at Trivandrum $\left(\Delta H_{\mathrm{TVM}}\right)$, a dip equatorial station and Alibag $\left(\Delta H_{\mathrm{ABG}}\right)$, an off-EEJ station (EEJ $\left.=\Delta H_{\mathrm{TVM}}-\Delta H_{\mathrm{ABG}}\right)$, are also shown for characterizing the equatorial east-west electric field. In addition, simultaneous $15 \mathrm{~min}$ averaged total electron content (TEC) measurements, as obtained using ground based GPS receivers over Trivandrum were also used for substantiating the results.

\section{Results}

\subsection{Geomagnetic conditions on August 24, 2005}

The storm which occurred during the period 23-26 August 2005 , i.e., declining phase of solar cycle 23 was unique in many ways (Ivanov \& Kharshiladze, 2007). Figure 1 shows the behavior of different interplanetary parameters and geomagnetic indices on August 24, $2005\left(A_{p}=102\right)$. In all the figures, time is expressed in Indian Standard Time (IST = Universal Time +5.5 h). From top to bottom, different panels represent EEJ, IMF Bz, ring current index (sym-H), the auroral electrojet $(A E)$ index, solar wind proton density $\left(N_{p}\right)$, proton temperature $\left(T_{p}\right)$ and the $X$ component of solar wind velocity $\left(v_{x}\right)$.

As is evident from the sym-H, the SSC occurred at around $\sim 11: 45$ IST, when the IMF Bz was steadily northward. The onset of the storm was at 14:45 IST on August 24, as indicated by the southward excursion of IMF $\mathrm{Bz}$, which reached its maximum value (negative maximum of IMF $\mathrm{Bz}=-51 \mathrm{nT}$ ) at $\sim 15: 30$ IST and turned northward at $\sim 16: 45$ IST. The aforementioned events at 11:45 and 14:45 IST, which created significant variability in the daytime equatorial upper atmosphere, are highlighted using the vertical dotted lines in Figure 1 and are discussed in the following sections.

\subsection{Response of the equatorial lonosphere}

The event of August 23-26 created a positive storm over the equatorial/low latitudes as described by Sreeja et al. (2009b). Following the SSC, a latitudinal expansion of the EIA has been noticed on August 24. It was attributed to the combination of different mechanisms such as uplifting of the plasma due to the penetration electric field, enhanced $\mathrm{O} / \mathrm{N}_{2}$ ratio and equatorward winds. In this study, importance is given to understand the role of SSC and PPEF on August 24 over the equator in the context of ionosphere-thermosphere coupling.

The signature of SSC in the magnetic field at Trivandrum ( 24 nT) and Trivandrum-Alibag ( 40 nT) was found to have the usual enhancement in amplitude over the dip equator. This enhancement in the present case was by a factor of about two, indicating that the EEJ is close to an average value. The ionosonde data of Trivandrum, as is evident from Figure 2 also showed an increase in hmF2 and a decrease in foF2, albeit after $\sim 10$ min (there was a break in data at around SSC). This increase in $\mathrm{hmF} 2$ is expected because of the short-duration penetration of eastward electric field that causes the dip equator enhancement of the SSC amplitude on the dayside through TM0 mode wave, as suggested by Kikuchi \& Araki (1979). This increase in hmF2 and decrease in foF 2 are distinctly discernable in comparison with the average quiet time pattern (average of five international quiet days, i.e., 2005 August 11, 20,30, 12 and 28) of hmF2 and foF2 in Figure 3b. To sum 


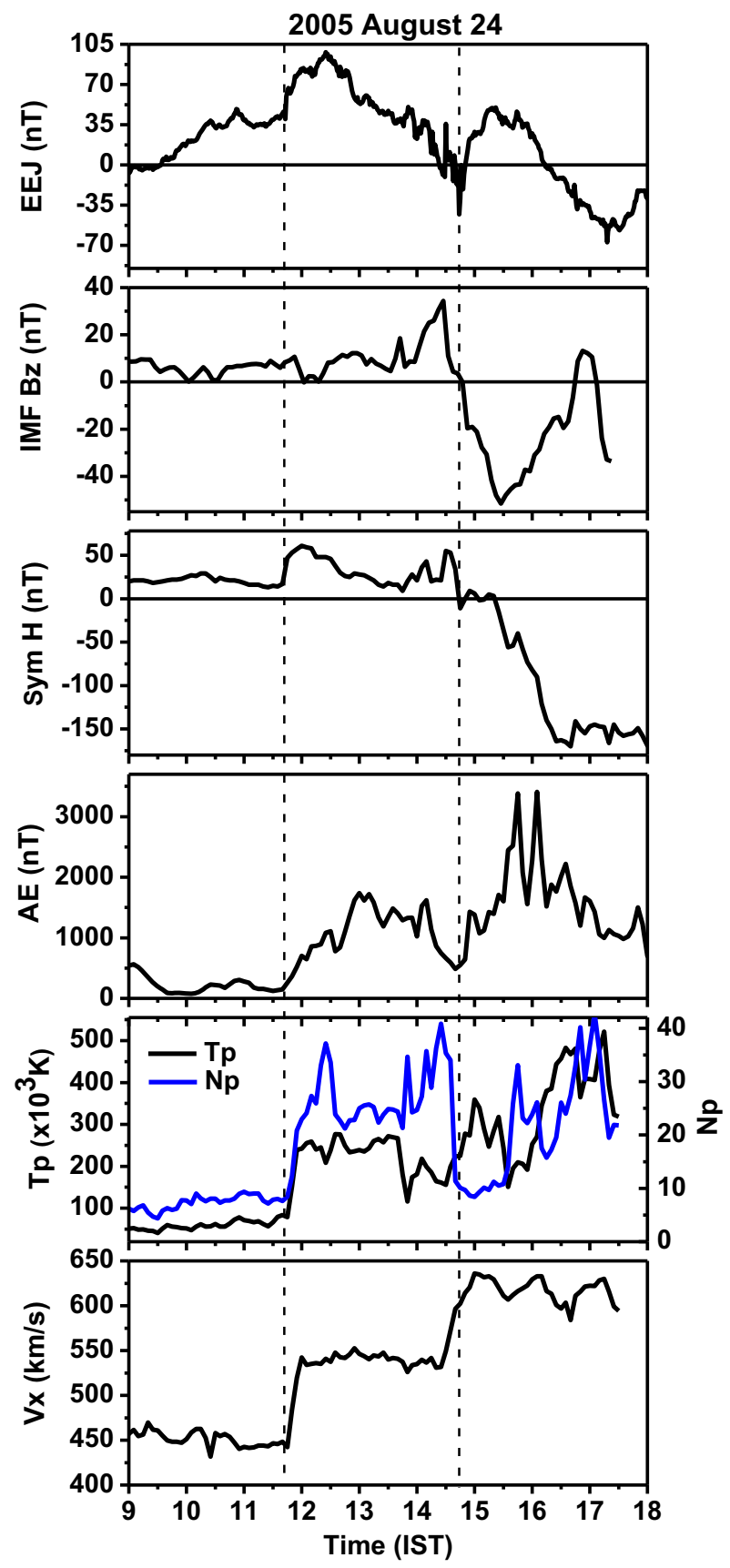

Fig. 1. Different panels are pertaining to the observations of the interplanetary and geomagnetic indices on August 24, 2005. From top to bottom, different panels are the equatorial electrojet (EEJ, IMF Bz, ring current index sym- $\mathrm{H}$, auroral electrojet index, solar wind Proton density and temperature, along with the $\mathrm{x}$ component of solar wind velocity.

up, the geomagnetic and ionosonde data are consistent with the prevailing understanding that during daytime, over the equator, the main impulse of SSC gets magnified due to the short-duration eastward field of high latitude origin.

The effects of this SSC related perturbation on August 24, 2005 continued until $\sim 12: 30$ IST and thereafter foF2 started a gradual increase, while $\mathrm{hmF} 2$ came down due to the decrease in prevailing daytime eastward electric field. The decrease in

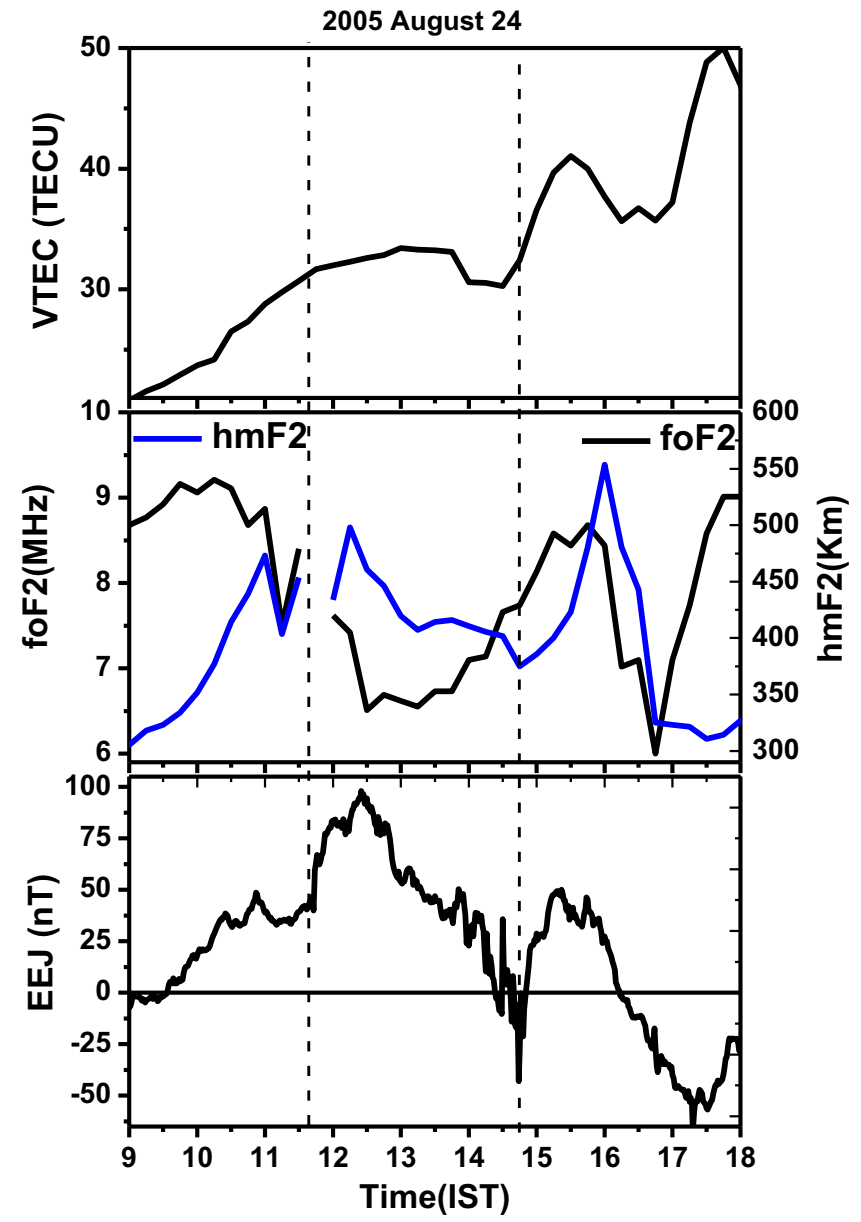

Fig. 2. The temporal evolution of GPS measured TEC (top panel), hmF2 and foF2 (middle panel) and the strength of EEJ (bottom panel).

hmF2 continued until the beginning of the main phase of the storm i.e., $\sim 14: 45$ IST.

At $\sim 14: 45$ IST, concomitant with negative (southward) excursion of the IMF Bz, the hmF2 showed an unusual increase, reaching to higher altitudes of $\sim 550 \mathrm{~km}$. This clearly shows the occurrence of an eastward penetration electric field. In fact, the effect of this PPEF continued until 16:30 IST, as evidenced by increased $\mathrm{hmF} 2$, which acquired its pre-penetration value after this time. Furthermore, the equatorial electric field as inferred using EEJ continued to be in the eastward direction until $\sim 16: 30$ IST. The foF2 and TEC also responded to this PPEF from $\sim 15: 30$ IST onwards, after $\sim 45 \mathrm{~min}$ as indicated by the decrease in TEC/foF2. In fact, TEC variability on August 24, 2005 was distinctly different from its average quiet time pattern (quiet time average of five international quiet days, i.e., 2005 August 11, 20, 30, 12 and 28) in Figure 3a. Furthermore, intensification of EIA after 15:30 IST and subsequent movement of EIA crest to higher latitudes (i.e., around $23^{\circ} \mathrm{N}$ ) as reported by Sreeja et al. (2009b), confirms this aspect. It is worthwhile to mention here that the penetrated electric field also led to the formation of F3 layers as is shown in Figure 4. The F3 layer appeared at $\sim 15: 45$ IST and continued until 16:15 IST, when hmF2 showed an increase due to the penetration electric field. The observed F3 layers, during this period are consistent with 


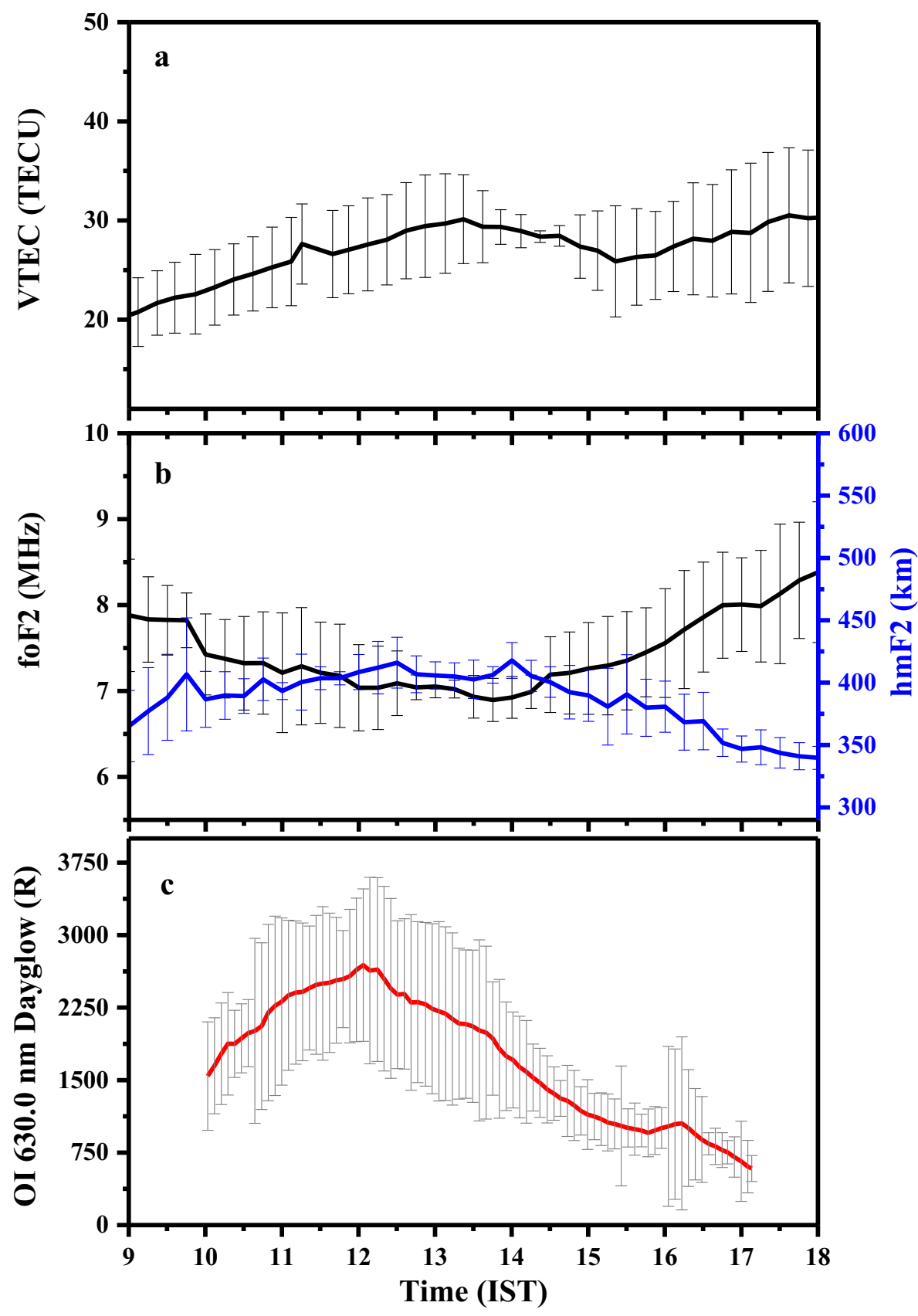

Fig. 3. The temporal evolution in the average quiet time variation of (a) GPS measured VTEC, (b) foF 2 and hmF2, and (c) OI $630.0 \mathrm{~nm}$ dayglow intensity. Error bars represent the standard deviations in all the plots.

previous studies of F3 layer during penetration events, which are produced as a result of meridional wind and PPEF (Balan et al., 1998). Such observations and a plausible mechanism of F3 layers are well explored in many of the earlier works (e.g., Paznukhov et al., 2007) and henceforth further description of F3 layer has not been included in this paper.

\subsection{Thermospheric observations using OI $630.0 \mathrm{~nm}$ dayglow}

Interestingly, the ground based thermospheric dayglow also responded definitively to the ongoing storm as shown in
Figure 5 (bottom panel). The dayglow intensity variation of August 24, 2005 for four different elevations in the southern direction is shown using different colors. The horizontal distances from the zenith sky $(0 \mathrm{~km})$ are also shown. In order to investigate the dayglow variability on August, 24, 2005 in conjunction with the prevalent conditions, the time evolution of solar wind ram pressure $\left(P_{\mathrm{sw}}\right)$, dawn-to-dusk component $E_{y}$ of IEF along with $X, Y$, and $Z$ components of Interplanetary magnetic field (IMF) are plotted in Figure 5. The daytime OI $630.0 \mathrm{~nm}$ airglow showed an entirely different pattern on this day in comparison with the average quiet time pattern in Figure 3c. 


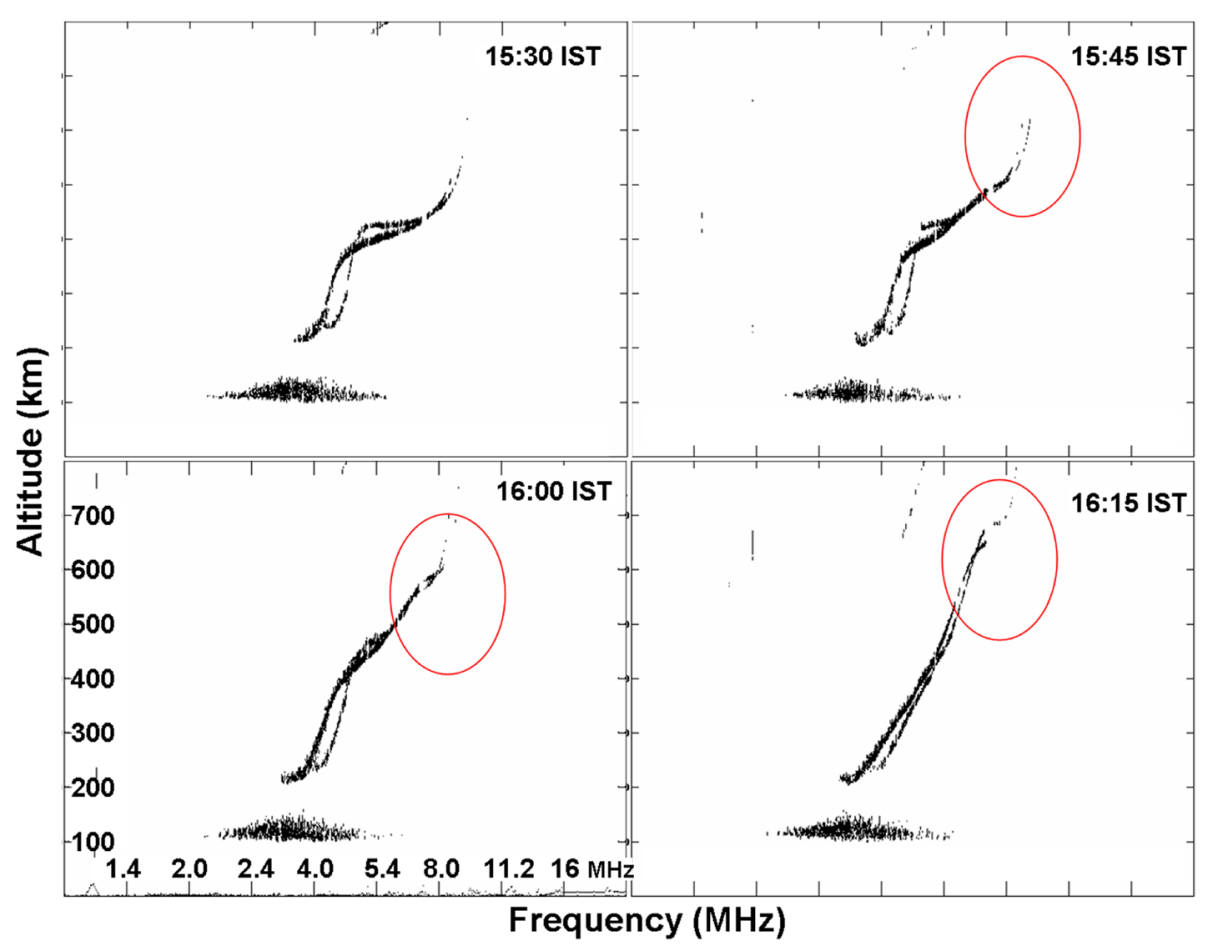

Fig. 4. Temporal evolution of F3 layers (shown in circles) over Trivandrum, as observed by the ionogram traces on August 24, 2005. The corresponding times in IST are shown in the top right corners.

As is evident from Figure 5, a sharp and prompt enhancement of $\sim 2000$ Rayleigh (R) in intensity at $\sim 11: 45$ IST was observed at all elevations in consonance with the abrupt increase in $P_{\mathrm{sw}}$, showing the arrival of a shock wave at the magnetopause. Thereafter, the OI $630.0 \mathrm{~nm}$ dayglow intensities exhibited a gradual decrease until $\sim 14: 45$ IST. Thereafter, airglow intensities registered an unusual depletion of $\sim 2000 \mathrm{R}$ until 16:30 IST. This strong depletion of emission started almost simultaneous to the reversal of dawn-dusk component of IEF. The IEF turned eastward at 14:45 IST, became strong $\sim 30 \mathrm{mV} / \mathrm{m}$ and continued eastward until $\sim 16: 30$ IST. The IMF $\mathrm{Bz}$ also showed concurrent variations with a sudden southward turning at $\sim 14: 30$ IST and remained strongly southward (-51 nT) until 16:30 IST. After 16:30 IST, a strong increase in the emission intensities can also be noticed, which is in fact more intense than the noon time value at some distances away from the zenith intensity.

The unusual depletion of this optical emission observed during the period 14:45-16:30 IST is not new. In fact, such drastic changes in the equatorial dayglow in conjunction with a number of penetration events and the corresponding physical mechanism have already been reported (Sumod et al., 2015). The observed depletion in the present case could be associated with the eastward PPEF which enhanced the plasma fountain over the equator due to the increased upward $\boldsymbol{E} \times \boldsymbol{B}$ drift. This further reduced the effective dissociative recombination at the emission altitudes resulting in substantial reduction in the dayglow intensity. The observed F3 layers during this period, as obvious from Figure 4 further supports the occurrence of a strong $\boldsymbol{E} \times \boldsymbol{B}$ drift. The abnormal increase in the dayglow intensity after $\sim 16: 30$ IST is attributed to the descent of $\mathrm{hmF} 2$ close to the emission altitudes, which increased the electron density and hence the dayglow intensity, as obvious from Figure 2. Nevertheless, the enhancement in the dayglow due to the increase in neutral density cannot be precluded in this context. In fact, the $\mathrm{O} / \mathrm{N}_{2}$ ratio, as measured by GUVI has indicated an enhanced value (1.5 times greater than that compared with quiet day) at 17:00 IST (Sreeja et al., 2009b). Therefore, it can be said that the observed increase in the dayglow intensity after 16:30 IST could be due to the combined effect of the decrease of $\mathrm{hmF} 2$ and the increase in $\mathrm{O} / \mathrm{N}_{2}$ at the emission altitudes.

The step like enhancement in the dayglow intensity at 11:45 IST is believed to be associated with the SSC. The temporal coincidence with the SSC cannot be ignored, particularly so because there are no significant changes in the IEF and $\mathrm{Bz}$ at that time. The ionosonde observations after the data break at 11:45 IST as well as the EEJ during the SSC indicated the presence of a short-duration eastward penetration electric field. This should have caused a reduction in dayglow intensity similar to that at $\sim 14: 45$ IST. However, our observations reveal an enhancement during this period. In fact, earlier rocket observations have also shown an enhancement in thermospheric temperature during the SSC (Gupta et al., 1986). However, such a scenario also should have created a reduction in the dayglow intensity. Nevertheless, it should be borne in mind that changes in dayglow would be strongly affected by the ongoing equatorial electrodynamics. As mentioned earlier, the short-duration penetration field associated with SSC can also lead to the enhanced airglow intensity, as more ionization is pumped to higher altitudes through the emission region, due to the increased vertical $\boldsymbol{E} \times \boldsymbol{B}$ drift. This additional ionization density can have enhanced the intensity of oxygen emission primarily due to the increased dissociative recombination at emission 


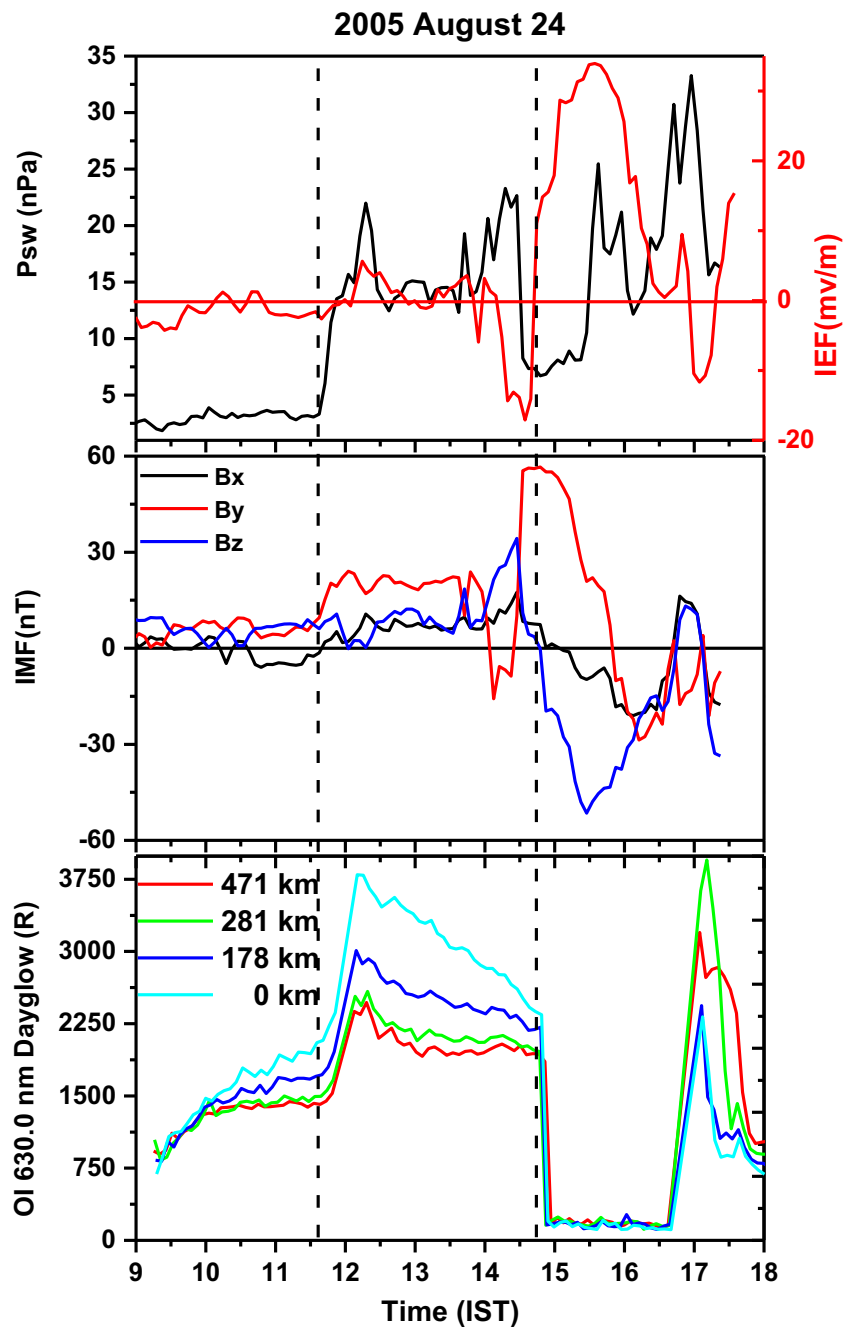

Fig. 5. The temporal evolution of solar wind ram pressure, interplanetary electric field (top panel), three components of IMF (middle panel) and the observed OI $630.0 \mathrm{~nm}$ dayglow intensity at four different elevations (bottom panel).

altitude. The observed gradual decrease in the airglow intensity after 12:15 IST can be associated with the diminishing effect of PPEF and dominant role of the equatorial field in controlling the distribution of plasma.

Although, SSC signatures in the dayglow may appear counterintuitive based on our earlier explanation of post-noon depletion, ensuing discussion will provide the plausible mechanism for such an unexpected behavior. Although both the penetrated electric field disturbances during SSC and PPEF are of the same polarity, they are distinctively different in two ways. Firstly, the SSC associated electric field is of shorter duration than that of PPEF, as expected which is responsible for the amplification of the main impulse of SSC (Sastri et al., 2001), whereas PPEF is of longer duration of $\sim 2 \mathrm{~h}$. Secondly, time of occurrence for both events over the dip equator are different, the former occurred during pre-noon hours, whereas the latter in the post-noon sector. Furthermore, it is to be noted that during daytime, OI $630.0 \mathrm{~nm}$ dayglow is produced due to three mechanisms viz, (i) photo electron impact of $\mathrm{O}$ by electrons of
$E>1.96 \mathrm{eV}$ (PE), (ii) Photo dissociation of $\mathrm{O}_{2}$ (PD) in the Schumann-Runge continuum, and (iii) dissociative recombination of $\mathrm{O}_{2}^{+}$(DR). It is generally believed that contributions from $\mathrm{PE}$ and PD in the temporal behavior of dayglow vary almost in consonance with solar zenith angle. They are not expected to show short duration $(<1 \mathrm{~h})$ fluctuations, unless the photoelectron flux and solar radiation changes drastically within that time scale. Therefore observed enhancement in the dayglow intensity during 11:45-12:15 IST can be understood as an additional contribution from DR in the overall intensity, which was already in the increasing trend due to PE and PD. Although the SSC associated electric field created a vertical plasma drift, it does not create any appreciable change in TEC. This indicates that the SSC associated electric field is not strong enough for creating a strong plasma fountain, thereby depleting the entire equatorial electron density. The hmF2 would have been a better index to indicate the penetration or extent of height rise, but unfortunately the data gap at 11:45 IST (i.e., during SSC) prevents us from making any comment. Nevertheless, the upward plasma drift would be sufficient to fill more electrons in the $150-350 \mathrm{~km}$ region, thereby increasing the dayglow intensity for a short duration of $\sim 30 \mathrm{~min}$, as seen in the present case. On the other hand, the post-noon PPEF, which occurred during the declining phase of PD and PE, was strong enough to affect the large scale phenomena EIA and resulted in the depletion of OI $630.0 \mathrm{~nm}$ dayglow for $\sim 2 \mathrm{~h}$.

Although, the present observations are explained on the basis of current understanding of equatorial thermosphereionosphere system (TIS), the results show that our knowledge on the SSC and its repercussions over the equatorial region, more precisely on the OI $630 \mathrm{~nm}$ dayglow is rather poor. Therefore coordinated ground based and satellite observations in tandem with theoretical studies are needed for the comprehensive understanding of TIS, especially during such transient events. In future, a chain of dayglow photometers are planned to be deployed at different latitudes along the Indian longitudinal sector, in tandem with GPS receivers. This would help to investigate space weather events with unprecedented spatial/ temporal resolution, particularly in the context of various electrodynamical processes such as EIA and ESF. In view of the above, we believe that these observations are very important, and perhaps for the "first time" shows the direct effect of SSC associated electric field on the optical emissions over the dayside dip equator.

\section{Concluding remarks}

The effects of SSC/IEF on the equatorial OI $630.0 \mathrm{~nm}$ dayglow are studied. It was understood that these dayglow emissions exhibit an unusual depletion associated with the overshielding electric field. It is consistent with the uplifting of the ionospheric $\mathrm{F}$ layer for the short duration of this penetration event. Furthermore, the signature of SSC over the equatorial thermosphere-ionosphere system has been identified using these optical features. Though the mechanism of SSC related effects in the dayglow is still not yet completely understood, the results are unique, and can have important consequences in understanding in the context of solar wind-magnetosphere-ionosphere coupling. In a complementary point of view, our results suggest the uniqueness of these dayglow emissions to investigate the 
space weather related issues with unprecedented temporal resolution.

Acknowledgements. This work was supported by Department of Space, Government of India. SSG acknowledges the research associateship from the Indian Space Research Organization. Discussions with C. Vineeth and M.M. Hossain are duly acknowledged. Authors also thank ACE team for providing the interplanetary data. The editor thanks Estefania Blanch and an anonymous referee for their assistance in evaluating this paper.

\section{References}

Balan N, Batista IS, Abdu MA, Macdougall J, Bailey GJ. 1998. Physical mechanism and statistics of occurrence of an additional layer in the equatorial ionosphere. J Geophys Res 103: 2916929181. DOI: $10.1029 / 98 J A 02823$.

Chakrabarti S. 1998. Ground based spectroscopic studies of sunlit airglow and aurora. J Atmos Sol-Terr Phys 60(14): 1403-1423. DOI: 10.1016/S1364-6826(98)00060-1.

Chakrabarty D, Sekar R, Chandra H, Narayanan R, Pathan BM, Subbarao KSV. 2002. Characterizations of the diurnal shapes of OI $630.0 \mathrm{~nm}$ dayglow intensity variations: Inferences. Ann Geophys 20(11): 1851-1855. DOI: 10.5194/angeo-20-1851-2002.

Chakrabarty D, Sekar R, Narayanan R, Pant TK, Niranjan K. 2004. Thermospheric gravity wave modes over low and equatorial latitudes during daytime. J Geophys Res 109: A12309. DOI: 10.1029/2003JA010169.

Chakrabarty D, Sekar R, Sastri JH, Pathan BM, Reeves GD, Yumoto K, Kikuchi T. 2010. Evidence for OI $630.0 \mathrm{~nm}$ dayglow variations over low latitudes during onset of a substorm. $J$ Geophys Res 115: A10316. DOI: 10.1029/2010JA015643.

Das U, Pallamraju D, Chakrabarti S. 2010. Effect of an X-Class solar flare on the OI $630 \mathrm{~nm}$ dayglow emissions. J Geophys Res 115: A08302. DOI: 10.1029/2010JA015370.

Gupta R, Desai JN, Raghava R, Sekar R, Sridharan R, Narayanan R. 1986. Excess heating over the equatorial latitudes during storm sudden commencement. Geophys Res Lett 13: 1055-1058. DOI: 10.1029/GL013i010p01055.

Ivanov KG, Kharshiladze AF. 2007. Solar-terrestrial extrastorm of August 22-25, 2005 I Solar sources. Geomagn Aeron 47: 27-32. DOI: $10.1134 / \mathrm{S} 0016793207010045$.

Kikuchi T, Araki T. 1979. Horizontal transmission of the polar electric field to the equator. J Atmos Sol-Terr Phys 41: 927-936. DOI: 10.1016/0021-9169(79)90094-1.

Pallamraju D, Sridharan R. 1998. High-resolution 2-D maps of OI $630.0 \mathrm{~nm}$ thermospheric dayglow from equatorial latitudes. Ann Geophys 16: 997-1006. DOI: 10.1007/s00585-998-0997-6.

Pallamraju D, Baumgardner J, Chakrabarti S. 2002. HIRISE: A ground-based high resolution imaging spectrograph using Echelle grating for measuring daytime airglow and auroral emissions. $J$ Atmos Solar-Terr Phys 64: 1581-1587. DOI: 10.1016/S1364-6826 (02)00095-0.

Pallamraju D, Chakrabarti S, Valladares CE. 2004. Magnetic storminduced enhancement in neutral composition at low latitudes as inferred by $\mathrm{O}\left({ }^{1} \mathrm{D}\right)$ dayglow measurements from Chile. Ann Geophys 22: 3241-3250. DOI: 10.5194/angeo-22-3241-2004.
Pallamraju D, Baumgardner J, Singh RP, Laskar FI, Mendillo C, Cook T, Lockwood S, Narayanan R, Pant TK, Chakrabarti S. 2014. Daytime wave characteristics in the mesosphere lower thermosphere region: Results from the balloon-borne investigations of regional-atmospheric dynamics experiment. J Geophys Res 119: 2229-2242. DOI: 10.1002/2013JA019368.

Paznukhov VV, Reinisch BW, Song P, Huang X, Bullett TW, Veliz O. 2007. Formation of an F3 layer in the equatorial ionosphere: A result from strong IMF changes. J Atmos Solar-Terr Phys 69: 1292-1304. DOI: 10.1016/j.jastp.2006.08.019.

Sastri JH, Takeuchi T, Araki T, Yumoto K, Tsunomura S, Tachihara H, Luehr H, Watermann J. 2001. Preliminary impulse of the geomagnetic storm sudden commencement of November 18, 1993. J Geophys Res 106: 3905-3918. DOI: 10.1029/ 2000JA000226.

Sreeja V, Vineeth C, Pant TK, Ravindran S, Sridharan R. 2009a. Role of gravity wavelike seed perturbations on the triggering of ESF - A case study from unique dayglow observations. Ann Geophys 27: 313-318. DOI: 10.5194/angeo-27-313-2009.

Sreeja V, Ravindran S, Pant TK, Devasia CV, Paxton L. 2009 b. Equatorial and low latitude ionosphere-thermosphere system response to the space weather event of August 2005. J Geophys Res 114: A12307. DOI: 10.1029/2009JA014491.

Sridharan R, Haider SA, Gurubaran S, Sekar R, Narayanan R. 1992. OI $630.0 \mathrm{~nm}$ dayglow in the region of equatorial ionization anomaly: Temporal variability and its causative mechanism. $J$ Geophys Res 97: 13715-13721. DOI: 10.1029/92JA00674.

Sridharan R, Pallam Raju D, Raghavarao R, Ramarao PVS. 1994. Precursor to equatorial spread-F in OI $6300 \mathrm{~nm}$ dayglow. Geophys Res Lett 21: 2797-2800. DOI: 10.1029/94GL02732.

Sridharan R, Modi NK, Pallam Raju D, Narayanan R, Pant TK, Taori A, Chakrabarty D. 1998. A multiwavelength daytime photometer a new tool for the investigation of atmospheric processes. Meas Sci Tech 9: 585-591. DOI: 10.1088/0957-0233/9/4/005.

Sridharan R, Taori A, Chakrabarty D, Chandra H, Sharma S, Narayanan R, Modi NK. 1999. Effects of 6 January 1997 space weather related processes in the low latitude thermosphere ionosphere system. J Atmos Sol Terr Phys 61: 1001-1005. DOI: 10.1016/S1364-6826(99)00063-2.

Sumod SG, Pant TK, Vineeth C, Hossain MM. 2011a. A new insight into the vertical neutral-ion coupling between the mesopause and ionosphere F region. Ann Geophys 29: 421-426. DOI: 10.5194/ angeo-29-421-2011.

Sumod SG, Pant TK, Vineeth C, Hossain MM, Antonita M. 2011 b. Response of tropical mesopause to the longest annular solar eclipse of this millennium. J Geophys Res 116: A06317. DOI: 10.1029/2010JA016326.

Sumod SG, Pant TK, Jose L, Hossain MM, Kumar KK. 2012. Signatures of sudden stratospheric warming on equatorial thermosphere-ionosphere system. Planet Space Sci 63-64: 49-55. DOI: 10.1016/jpss201108005.

Sumod SG, Pant TK, Vineeth C, Hossain MM. 2014. On the ionospheric and thermospheric response of solar flare events of 19 January 2005: An investigation using radio and optical techniques. J Geophys Res 119: 5049-5059. DOI: 10.1002/2013JA019714.

Sumod SG, Pant TK, Vineeth C, Hossain MM. 2015. Unusual depletion of OI $630.0 \mathrm{~nm}$ dayglow and simultaneous heating during the penetration of interplanetary electric field over dip equator. $J$ Geophys Res 120: 2110-2117. DOI: 10.1002/2014JA020584.

Cite this article as: Sumod SNGK, Pant TK \& Ajesh A 2019. Signatures of Sudden Storm Commencement on the equatorial thermospheric dayglow. J. Space Weather Space Clim. 9, A31. 